American Journal of Biotechnology and Biochemistry 4 (1): 35 -42, 2008

ISSN 1553-3468

(C) 2008 Science Publications

\title{
Effect of Yoga and Traditional Physical Exercise on Hormones and Percentage Insulin Binding Receptor in Patients with Type 2 Diabetes
}

\author{
${ }^{1}$ Lorenzo Gordon, ${ }^{2}$ Errol York Morrison, ${ }^{3}$ Donovan McGrowder, ${ }^{1}$ Yeiny Fraser Penas, ${ }^{4}$ Eslaen Martorell \\ Zamoraz, ${ }^{5}$ David Garwood, ${ }^{2}$ Ruby Alexander-Lindo and ${ }^{2}$ Rachael Irving \\ ${ }^{1}$ Department of Medicine, University Hospital of the West Indies, Kingston 7, Jamaica \\ ${ }^{2}$ Department of Basic Medical Sciences, University of the West Indies, Kingston 7, Jamaica \\ ${ }^{3}$ Department of Pathology, University of the West Indies, Kingston 7, Jamaica \\ ${ }^{4}$ Saturnino Lora Hospital, Santiago de Cuba, Cuba \\ ${ }^{5}$ Cornwall Regional Hospital, Montego Bay, Kingston 7, Jamaica
}

\begin{abstract}
The objective of the study was to investigate the short-term impact of a brief lifestyle intervention of yoga and traditional Physical Training (PT) exercise regimens on: serum insulin, percentage insulin binding receptor, internalization of insulin-receptor complex, $\mathrm{T}_{3}, \mathrm{~T}_{4}, \mathrm{TSH}$ and cortisol at baseline, 3 months and 6 months in patients with type 2 diabetes mellitus. A total of 231 patients completed this prospective randomized study with 77 type 2 diabetic patients in the yoga group (62 females and 15 males) that were matched with the same number of patients in the traditional Physical Training (PT) exercise and control groups. Biochemical parameters such as fasting Blood Glucose (FBG), serum insulin, percentage insulin binding receptor and internalization of insulinreceptor complex were determined at the beginning (baseline) and two consecutive three monthly intervals. The effect of the lifestyle interventions on hormones such as cortisol, $\mathrm{TSH}, \mathrm{T}_{4}$ and $\mathrm{T}_{3}$ were also investigated. The FBG concentration in the yoga and the traditional PT exercise groups were markedly decreased compared with control $(\mathrm{P}<0.05)$. The percentage of insulin binding receptor increased in the yoga and traditional PT exercise groups at the sixth month when compared to baseline and this parameter in the traditional PT exercise group differs significantly from that of the control group at the six month $(\mathrm{P}=0.024)$. There was no significant difference in the percentage of internalization of the insulin receptor complex amongst the three groups $(\mathrm{P}=0.465)$. There was no significant change in $\mathrm{T}_{3}, \mathrm{~T}_{4}$, TSH or cortisol in any of the three groups over the six month period $(\mathrm{P}>$ 0.05). The findings indicates the beneficial effects of yoga and traditional PT exercise regimens in improving glycaemic control by increasing percentage insulin binding receptor in type 2 diabetic patients with no significant change in cortisol and thyroid hormones.
\end{abstract}

Keywords: Diabetes mellitus, yoga, physical exercise, glucose, insulin receptor

\section{INTRODUCTION}

Type 2 diabetes mellitus is a heterogeneous disorder, characterized by a genetic predisposition and interaction between insulin resistance and decreased pancreatic beta-cell function ${ }^{[1]}$. It is frequently associated with other conditions such as hypertension, hypertriglyceridaemia and decreased high-density lipoprotein (HDL) which are additional risk factors for atherosclerosis and cardiovascular disease $(\mathrm{CVD})^{[2]}$. Individuals with type 2 diabetes and poor glycaemic control may develop severe microvascular complications of diabetes including retinopathy, nephropathy and neuropathy ${ }^{[3]}$. Appropriate diet, weight control and increased physical activity will increase insulin sensitivity in insulin resistant patients and are effective treatments for patients with type 2 diabetes mellitus or may prevents its development in susceptible individuals ${ }^{[4]}$. Exercise training in humans results in numerous beneficial adaptations in skeletal muscles, including an increase in glucose transporter-4 (GLUT-4) expression. A single bout of exercise increases the rate of glucose uptake into the contracting skeletal muscles, a process that is regulated by the

Corresponding Author: $\quad$ Dr. Lorenzo Gordon, Department of Medicine, University of the West Indies, Kingston 7, Jamaica W.I. Tel: + 876 - 927 - 1620- 9, Fax: + 876-977-1811 
translocation of GLUT-4 to the plasma membrane and transverse tubules ${ }^{[5]}$. There is evidence that exercise stimulates muscle glycogen synthesis, increases insulin sensitivity, reduces blood glucose levels ${ }^{[6]}$ and has other benefits such as stimulation of the production of betaendorphin $^{[7]}$.

The insulin receptor has been implicated in the pathogenesis of obesity and obesity-related disorders, while insulin resistance is associated with other diseases such as dyslipidemia and type 2 diabetes mellitus ${ }^{[8]}$. Hyperinsulinemia induces insulin receptor loss by means of the down-regulation mechanism, and prolonged hyperglycaemia may induce the impairment of insulin receptor kinase in the skeletal muscles. These dysfunctions in insulin signaling may cause the deterioration of insulin sensitivity, resulting in worsening glycaemic control ${ }^{[9]}$. The function of insulin receptors and the internalization of insulin receptor complex are particularly affected in type 2 diabetes mellitus ${ }^{[10]}$. There are authors who have suggested that insulin internalization into cells and intracellular insulin processing are altered in individuals with type 2 diabetes mellitus and these problems may play a role in the cellular resistance to insulin that occurs in the groups of patients studied ${ }^{[11,12]}$.

Diabetes mellitus constitutes essentially an endocrinologic problem in which many glands are implicated. The monitoring of hormones such as insulin, cortisol, 3,5,3'triiodothyronine $\left(\mathrm{T}_{3}\right)$ and thyroxine $\left(\mathrm{T}_{4}\right)$ (thyroid) and thyroid-stimulating hormone (TSH) are very important to characterize the endocrinologic function in type 2 diabetes $^{[13]}$. There is a profound relationship among the thyroid, adrenal and pituitary glands in the initiation and progress of diabetes mellitus and there are several interconnecting points amongst them. These relationships can determine many alterations, including the changes in the degree of glucose tolerance, which represent a risk factor for cardiovascular diseases (CVD), type 2 diabetes mellitus and stroke $e^{[14]}$.

Yoga is an ancient Indian science and a number of controlled studies exist on the effectiveness of yoga. These investigations include such conditions as cardiovascular disease ${ }^{[15,16]}$ and diabetes mellitus ${ }^{[17]}$. A study by Agrawal and colleagues demonstrated significant reduction in oral hypoglycaemic agents and insulin after yoga life style intervention ${ }^{[18]}$. Few studies have examined the effect of yoga on insulin and glucoregulatory hormones. This study evaluated the effects of yoga and traditional physical training (PT) exercise regimens on fasting blood glucose, serum insulin, percentage insulin binding receptor and internalization of insulin-receptor complex at baseline, 3 months and 6 months in individuals with type 2 diabetes mellitus. In addition we also evaluated the effect of these two exercise regimens on cortisol, TSH, $\mathrm{T}_{4}$ and $\mathrm{T}_{3}$ in the same time period.

\section{MATERIALS AND METHODS}

Subjects: This prospective randomized control study was conducted at The National Institute of Endocrinology and The "Hermanos Ameijeiras" Hospital, Havana, Cuba from September to December 1998. The patients were selected according to the CONSORT declaration ${ }^{[19]}$ and include only those with type 2 diabetes who had been trained in diabetes education and instruction, exercise, diet and medication according to the recommendations of the International Diabetes Federation (IDF), for a minimum of 3 months, and who met the following criteria for the study. These criteria are: type 2 diabetes mellitus without malnutrition or severe complications of the disease (cardiovascular, renal, visual and cerebral), between 40-70 years old, duration of the disease between 1-10 years, good psychological condition (in accordance with the psychologist's consideration) and do not smoke or take excessive alcohol. The study was approved by The "Hermanos Ameijeiras" Hospital ethics committee and informed consent was obtained from all patients who participated in the study.

A total of 231 subjects were recruited for this prospective randomized study: 77 type 2 diabetic patients in the yoga group (62 females and 15 males) that were matched with 77 type 2 diabetic patients in the traditional PT exercise group (62 females and 15 males) and another 77 type 2 diabetic patients serving as the control group (62 females and 15 males). The traditional PT exercise group followed the treatment as recommended by the IDF, based on education, instruction, diet, exercise, and medication. The yoga group also applied the criteria of the IDF programme based on education, instruction, diet and medication but instead of traditional PT exercise, the yoga programme of exercise was followed. The control group followed a treatment plan as recommended by their clinics or general physicians and was never seen by the personnel of this study for diabetes management. They were not engaged in any kind of exercise during the entire study period. The managed groups (traditional PT and yoga) were trained for 24 weeks in basic exercise technique, and diabetes education and instructions. These programmes were carefully illustrated through 
workshops. Each managed group fulfilled a specific weekly programme that included the following: medical and psychological evaluation of patients with alterations, instructions on: education, diet, specific treatments, personal care and exercises (traditional PT or yoga) of 2 hours duration daily.

Biochemical assays: The hormones evaluated were: insulin, cortisol, TSH, $\mathrm{T}_{4}$ and $\mathrm{T}_{3}$. TSH level was determined by immunoradiometric assay ${ }^{[20]}$ using the lymphocyte model by techniques of radioimmuno assay $^{[21]}$. Cortisol level was also determined by radioimmunoassay ${ }^{[22]}$. Twenty (20) $\mathrm{mL}$ of blood was drawn into heparinized tubes after an overnight fast $(12 \mathrm{~h})$. The sample was centrifuged at $2400 \mathrm{rpm}$ and then the plasma and the layer of white cells were extracted. The plasma was frozen and transferred to other sections of the laboratory to determine other parameters. The layer of white cells was gently reconstituted with $3 \mathrm{~mL}$ of saline solution in order to obtain lymphocytes. This was then mixed with $3 \mathrm{~mL}$ of FICOLL-PAQUE (Merk), centrifuged carefully at $1200 \mathrm{rpm}$ for 30 minutes. The lymphocytes were extracted from the interface with a Pasteur pipette, washed gently three times with saline solution and the final concentration adjusted to 5 million cells $/ \mathrm{mL}$.

Insulin binding to the lymphocytes was measured according to the technique (modified) by Gambir and colleagues $^{[23]}$. To determine the total radioactivity 400 $\mu \mathrm{L}$ of the cell suspension (concentration of 5 million cells), $50 \mu \mathrm{L}(288.5 \mathrm{pg})$ of monoiodinated ${ }^{125}$ I-insulin and $50 \mu \mathrm{L}$ tampon $\mathrm{G}$ were added in a tube. The total radioactivity was determined using a Gamma Counter. To determine the non-specific binding $400 \mu \mathrm{L}$ of the cell suspension (concentration of 5 million cells), $50 \mu \mathrm{L}$ of monoiodinated ${ }^{125} \mathrm{I}$-insulin and $100,000 \mathrm{ng} / \mathrm{mL}$ of non-marked insulin mixed with $50 \mu \mathrm{L}$ tampon $\mathrm{G}$ were added to 2 tubes. Both tubes were incubated at $37{ }^{\circ} \mathrm{C}$ for 3 hours. The excess supernatant was discarded and $700 \mu \mathrm{L}$ of dibutyl phthalate added. It was centrifuged at $1100 \mathrm{rpm}$ for 2 minutes. The supernatant was discarded. The reactivity associated with the precipitate was determined using a Gamma Counter. The specific binding was calculated as: specific binding = radioactivity of the non specific binding/total radioactivity ( $\mathrm{x}$ 100\%). To determine the internalization of the insulin-receptor complex, the same procedure (by Ghambir and colleagues) was applied. The incubation was for 3.5 hours after which $0.5 \mathrm{mLs}$ of $10 \%$ tricloroacetic acid (TCA) and bovine serum albumin (BSA) were added. The tubes were centrifuged at $1100 \mathrm{rpm}$ and the supernatant was discarded. The reactivity associated with the precipitate was determined using a Gamma Counter, after which the internalized radioactivity was counted ${ }^{[23]}$.

Statistical analysis: After the data was collected and recorded on questionnaires, a database was developed in Microsoft Excel 2000. The calculations were carried out with the soft-wares EPI-INFO Version 6.0 and SPSS Version 10.0 with a level of statistical significance of $95 \%$. The individual variables were studied to determine the changes in the three groups (traditional PT exercise, yoga and control) during the different periods (at 0,3 and 6 months). To investigate the effects of a variable within a group the Within Subjects factors analysis, and the effects between groups the Between - Subjects analysis were used according to the Two Way ANOVA with 95\% confidence. Two Way ANOVA was applied to detect differences among and within groups (traditional PT exercise, yoga and control) over the duration of the treatment. According to the behaviour of the variables, each table was represented by the mean and the standard error of the mean (SEM). As the three groups were of equal sizes then the Tukey's Honestly Significant Difference (Tukey HSD, available in SPSS) was used. Differences were considered significant if $P$ $<0.05$.

\section{RESULTS}

There were 231 type 2 diabetic patients, 186 (80.5\%) females (62 in the traditional PT exercise group, 62 in the yoga group and 62 in the control group) and $45(19.5 \%)$ males (15 in the traditional PT exercise group, 15 in the yoga group and 15 in the control group). Subjects were matched according to age and sex and the mean ages were very similar in the three groups according to gender (Table 1).

Table 1: Frequency of treated type 2 diabetic subjects according to group, sex and age

\begin{tabular}{lllllll}
\hline Group & $\begin{array}{l}\text { Female } \\
\text { No. Mean } \\
\text { Age }\end{array}$ & \multicolumn{2}{c}{$\begin{array}{l}\text { Male } \\
\text { No. Mean } \\
\text { Age }\end{array}$} & $\begin{array}{l}\text { Total } \\
\text { No. Mean } \\
\text { Age }\end{array}$ \\
\hline Trad. & 62 & 62.3 & 15 & 65.8 & 77 & 63.9 \\
Yoga & 62 & 63.8 & 15 & 64.7 & 77 & 64.0 \\
Control & 62 & 63.8 & 15 & 62.5 & 77 & 63.6 \\
\hline
\end{tabular}


All groups at baseline exhibited a similar state of hyperglycaemia. In the traditional PT exercise yoga groups there were decreased concentrations of fasting blood glucose (FBG) at the third and sixth months of exercise (Table 2). The concentrations of FBG in the yoga group (from $11.84 \pm 0.45 \mathrm{mmol} / \mathrm{L}$ at baseline to $8.35 \pm 0.44 \mathrm{mmol} / \mathrm{L}$ at the sixth month) and the traditional PT exercise group (from $11.74 \pm 0.34$ $\mathrm{mmol} / \mathrm{L}$ at baseline to $8.52 \pm 0.24 \mathrm{mmol} / \mathrm{L}$ at the sixth month) were markedly decreased compared with the control group (from $11.77 \pm 0.44 \mathrm{mmol} / \mathrm{L}$ at baseline to $10.89 \pm 0.39 \mathrm{mmol} / \mathrm{L}$ at the sixth month). There was no significant difference $(\mathrm{P}>0.05)$ in $\mathrm{FBG}$ concentration between the traditional PT exercise and yoga groups. However, there were significant differences in FBG between the managed groups and the control group at the third and sixth months $(\mathrm{P}<0.05)$.

Table 2: Comparison of FBG concentration and insulin level among traditional PT exercise, yoga and control type 2 diabetic patients in a 6-month period

\begin{tabular}{lccc}
\hline $\begin{array}{l}\text { Variable/ } \\
\text { Group }\end{array}$ & Baseline & 3 Months & 6 Months \\
\hline FBG (mmol/L) & & & \\
& & & \\
Traditional & $11.74 \pm 0.34$ & $* 8.71 \pm 0.24$ & $* 8.52 \pm 0.24$ \\
Yoga & $11.84 \pm 0.45$ & $* 8.58 \pm 0.44$ & $* 8.35 \pm 0.44$ \\
Control & $11.77 \pm 0.44$ & $12.79 \pm 0.37$ & $10.89 \pm 0.39$ \\
Insulin (mU/L) & & \\
Traditional & $17.23 \pm 1.43$ & $17.39 \pm 1.45$ & $17.20 \pm 1.80$ \\
Yoga & $17.60 \pm 1.53$ & $17.51 \pm 1.65$ & $17.27 \pm 1.81$ \\
Control & $17.10 \pm 1.44$ & $18.28 \pm 1.64$ & $18.04 \pm 1.67$ \\
\hline
\end{tabular}

Statistical significant differences are indicated by $* \mathrm{P}<$ 0.05 vs control at the third or at the sixth month.

In the control the mean level of cortisol decreased at the sixth month with value of $514.59 \pm$ $22.90 \mathrm{mU} / \mathrm{L}$ compared to $521.01 \pm 23.37 \mathrm{mU} / \mathrm{L}$ at baseline. There was minimal change in the cortisol level in the yoga and traditional PT exercise groups (P $>0.05$; Table 3). Although there were no significant differences $(\mathrm{P}=0.082)$ in the percentage of insulin binding receptor amongst the groups there was a significant effect when the Two Way ANOVA and the within - subjects factors analysis were applied in which the combination time and exercise had a significant effect $(\mathrm{P}=0.040$; Table 3$)$.
Table 3: Comparison of cortisol level, percentage insulin receptor binding and internalization of the insulin-receptor complex among traditional PT exercise, yoga and control type 2 diabetic patients in a 6-month period

\begin{tabular}{lrr}
\hline $\begin{array}{l}\text { Variable/ } \\
\text { Group }\end{array}$ & \multicolumn{1}{l}{ Baseline } & \multicolumn{1}{l}{ 6 Months } \\
\hline $\begin{array}{l}\text { Cortisol (mU/L) } \\
\text { Traditional }\end{array}$ & $521.74 \pm 21.87$ & $522.05 \pm 20.77$ \\
Yoga & $524.84 \pm 23.98$ & $523.49 \pm 24.01$ \\
Control & $521.01 \pm 23.71$ & $514.59 \pm 22.90$ \\
Insulin Binding & & \\
Receptor (\%) & & \\
Traditional & $0.30 \pm 0.01$ & $* 0.33 \pm 0.02$ \\
Yoga & $0.29 \pm 0.02$ & $* 0.32 \pm 0.02$ \\
Control & $0.29 \pm 0.01$ & $0.26 \pm 0.02$ \\
Internalization & & \\
of Insulin- & & \\
Receptor Complex (\%) & \\
Traditional & $0.65 \pm 0.00$ & $0.69 \pm 0.02$ \\
Yoga & $0.66 \pm 0.01$ & $0.68 \pm 0.02$ \\
Control & $0.65 \pm 0.01$ & $0.66 \pm 0.01$ \\
\hline Statical significan
\end{tabular}

Statistical significant differences are indicated by $* \mathrm{P}<$ 0.05 vs control at the third or at the sixth month.

The percentage of insulin binding receptor increased in the traditional PT exercise and yoga groups at the sixth month when compared to baseline while it decreased in the control group (Table 3). In the traditional PT exercise group the percentage of insulin binding receptor increased from $0.30 \pm 0.01 \%$ from baseline to $0.33 \pm 0.02 \%$ at the sixth month and in the yoga group it increased from $0.29 \pm 0.02 \%$ to $0.32 \pm$ $0.02 \%$. The percentage of insulin binding receptor decreased from $0.29 \pm 0.01 \%$ to $0.26 \pm 0.02 \%$ in the control group. The Tukey HSD test revealed that the mean percentage insulin binding receptor was not significantly different between the traditional PT exercise and the yoga groups at the third and sixth months $(\mathrm{P}>0.05)$. However the percentage insulin binding receptor in the traditional PT exercise group differed significantly from that of the control group at the six month $(\mathrm{P}=0.024)$. There was no significant difference in the percentage of internalization of the insulin-receptor complex among the three groups $(\mathrm{P}=$ $0.465)$, however, within - subjects factors analysis showed that time had a significant effect $(\mathrm{P}=0.046)$. 
The percentage of the internalization insulin-receptor complex increased from $0.65 \pm 0.00 \%$ at baseline to $0.69 \pm 0.02 \%$ at the sixth month in the traditional PT exercise group and from $0.66 \pm 0.01 \%$ at baseline to $0.68 \pm 0.02 \%$ at the sixth month in the yoga group. There was a slight increase in the control group from $0.65 \pm 0.01 \%$ at baseline to $0.66 \pm 0.01 \%$ at the sixth month (Table 3).

There was no significant change in $\mathrm{T}_{3}, \mathrm{~T}_{4}$ or TSH in the type 2 diabetic patients in any of the three groups over the six month period $(\mathrm{P}>0.05)$. In the traditional $\mathrm{PT}$ exercise group the mean level of $\mathrm{T}_{3}$ was $3.27 \pm 0.01$ $\mathrm{nmol} / \mathrm{L}$ at the baseline and at the sixth month while in the yoga group it was $3.26 \pm 0.11 \mathrm{nmol} / \mathrm{L}$ at the three time points (Table 4). The levels of $\mathrm{T}_{4}$ were similar at the different time points in the three groups. In the traditional group the mean level of $\mathrm{T}_{4}$ was $90.56 \pm 3.58$ $\mathrm{nmol} / \mathrm{L}$ at baseline and $91.33 \pm 3.52 \mathrm{nmol} / \mathrm{L}$ at the sixth month. In the yoga group the level of $\mathrm{T}_{4}$ was $88.85 \pm$ $3.42 \mathrm{nmol} / \mathrm{L}$ at baseline and $88.36 \pm 3.27 \mathrm{nmol} / \mathrm{L}$ at the sixth month. In the control group the level of $\mathrm{T}_{4}$ was $87.39 \pm 3.64 \mathrm{nmol} / \mathrm{L}$ at baseline and $89.41 \pm 3.65$ $\mathrm{nmol} / \mathrm{L}$ at the sixth month $(\mathrm{P}>0.05)$. The mean level of TSH was $1.42-1.47 \mu \mathrm{U} / \mathrm{mL}$ in the three groups at the different points of treatment and did not show any variation that was significant $(\mathrm{P}<0.05)$.

\section{DISCUSSION}

Exercise is a major therapeutic modality in the treatment of type 2 diabetes mellitus and prevention of complications ${ }^{[24]}$. The present study showed that yoga and traditional PT exercise regimens caused improvement in glycaemic control due to increased percentage insulin binding receptor in patients with type 2 diabetes mellitus. Few studies have examine the effect of yoga exercise on gluco-regulation ${ }^{[25,26]}$. Sahay reported that the beneficial effects of yoga observed in persons with type 2 diabetes mellitus included significant decrease in fasting and postprandial blood glucose concentrations, decreased cholesterol and fatty acid concentration, and decreased levels of serum cortisol $^{[26]}$. According to the author, the favourable changes observed may be due to a combination of factors such as exercise, changes in metabolic factors, changes in kinetics of insulin and counter-regulatory hormones such as cortisol and glucagon ${ }^{[26]}$.
Table 4: Comparison of $\mathrm{T}_{3}, \mathrm{~T}_{4}$ and TSH levels traditional PT exercise, yoga and control type 2 diabetic patients in a 6-month period

\begin{tabular}{llll}
\hline $\begin{array}{l}\text { Variable/ } \\
\text { Group }\end{array}$ & Baseline & 3 Months & 6 Months \\
\hline T3 $(\mathrm{nmol} / \mathrm{L})$ & & & \\
Traditional & $3.27 \pm 0.01$ & $3.26 \pm 0.01$ & $3.27 \pm 0.01$ \\
Yoga & $3.26 \pm 0.11$ & $3.26 \pm 0.05$ & $3.26 \pm 0.01$ \\
Control & $3.31 \pm 0.01$ & $3.31 \pm 0.01$ & $3.30 \pm 0.01$ \\
T4 (nmol/L) & & & \\
Traditional & $90.56 \pm 3.58$ & $90.63 \pm 3.58$ & $91.33 \pm 3.52$ \\
Yoga & $88.85 \pm 3.42$ & $88.91 \pm 3.42$ & $88.36 \pm 3.27$ \\
Control & $87.39 \pm 3.64$ & $88.02 \pm 3.64$ & $89.41 \pm 3.65$ \\
TSH $(\mu \mathrm{U} / \mathrm{ml})$ & & & \\
Traditional & $1.43 \pm 0.14$ & $1.43 \pm 0.15$ & $1.44 \pm 0.13$ \\
Yoga & $1.43 \pm 0.01$ & $1.44 \pm 0.01$ & $1.43 \pm 0.01$ \\
Control & $1.42 \pm 0.13$ & $1.47 \pm 0.14$ & $1.44 \pm 0.12$ \\
\hline
\end{tabular}

Cortisol is the main hormone secreted by the adrenal gland. It influences the metabolism of carbohydrates, proteins and fatty acids, the maturation of the leukocytes of the blood, the retention of salts and water, the activity of the nervous system and the regulation of arterial pressure. The determination of cortisol can be used to characterize the status of the hypothalamic-pituitary-adrenal axis ${ }^{[13]}$. In a study by Kamei and colleagues serum cortisol levels were decreased during yoga exercise and this was correlated with increased alpha wave activation ${ }^{[27]}$. In our study there was no significant change in cortisol levels at baseline compared with the value at the sixth month in any of the three groups.

It is well-established that the percentage of insulin receptors and internalization of insulin- receptor complex are particularly diminished in individuals with type 2 diabetes mellitus ${ }^{[28]}$. The beneficial influence of yoga and traditional PT exercise regimens in the control of glycaemia in individuals with type 2 diabetes mellitus may be attributed to their ability to increase the percentage of insulin receptor binding at the sixth month compared with baseline. Therefore interventions favours the initial action of insulin (binding to specific protein receptors located on the cell plasma membrane) and to a lesser extent increase internalization of the insulin receptor complex. Hence, yoga and traditional PT exercise may delay the progress of type 2 diabetes mellitus by reducing hyperglycaemia and hyperinsulinaemia. This would reduce the use of other sources of energy such as lipids and proteins by the cells and so avoid or diminish hypertriglycedaemia. In a study by Sahay of patients with uncontrolled type diabetes mellitus at the end of 4 weeks there was a 
significant increase in the insulin receptors, although the blood glucose did not normalize ${ }^{[29]}$ indicating a reduction in insulin resistance and an improvement in insulin sensitivity ${ }^{[25]}$.

Abnormalities of both insulin secretion and insulin action occur in type 2 diabetes mellitus ${ }^{[30]}$. The study of the changes in insulin concentrations may help to explain the possible influence of yoga on the metabolic control of type 2 diabetes mellitus. The high level of insulin may be considered as evidence of insulin resistance $^{[31]}$ and is strongly related to cardiovascular risk factors in diabetic and non-diabetic subjects ${ }^{[32]}$. The relationship between physical activity and type 2 diabetes mellitus appears to be mediated by true serum insulin level ${ }^{[33]}$ and this can be associated with obesity ${ }^{[34]}$ which may be due to the insulin promoting cholesterol synthesis ${ }^{[35]}$ and may accompany the alteration of other lipid profiles ${ }^{[36]}$. In this study there was no significant change in the serum insulin levels even though there was a decrease in fasting blood glucose concentrations. In a recent study by Sahay, yoga asanas caused a significant decrease in fasting and postprandial glucose. There was a shift of the peak level of insulin to the left and there was a normalization of the insulin/glucose ratio with a reduction in the free fatty acid levels suggesting a better peripheral utilization of insulin ${ }^{[29]}$. The beneficial effect of yoga asanas on the insulin kinetics and the lipid metabolism prevents the exhaustion of the beta-cell and the development of a beta-cell secretory defect, thereby preventing the development of type 2 diabetes mellitus $^{[3]}$. Manjunatha and colleagues performed a similar study in healthy volunteers and reported that serum insulin levels after yoga asanas were lower than before. In addition, serum insulin levels were higher after post-asana oral $75 \mathrm{~g}$-glucose challenge ${ }^{[38]}$. The observations suggested that the performance of yoga asanas led to an increase in insulin sensitivity of betacells of the pancreas to the glucose signal which could explain the mechanism by which yoga asanas have a beneficial effect on diabetes mellitus ${ }^{[37]}$.

The function of $T_{3}$ and $T_{4}$ includes increasing the rate of the metabolism of carbohydrates and fats, as well as the synthesis and degradation of proteins inside the cell. $\mathrm{T}_{3}$ regulates the synthesis of many glucolytic enzymes like alpha-glycerol-phosphate dehydrogenase which intervenes at fundamental points of the degradation of glucose ${ }^{[39]}$. It has been demonstrated that the mean value of serum $T_{3}$ is significantly decreased in diabetic patients compared to that of normal controls. The concentration of serum $\mathrm{T}_{3}$ is negatively correlated with fasting blood glucose level and the increase in $\mathrm{T}_{3}$ receptor binding capacity reflects the compensatory mechanisms which are probably evoked by $\mathrm{T}_{3}$ deficiency to maintain cellular homeostasis ${ }^{[40]} \cdot \mathrm{T}_{4}$ has a permissive role in the cellular internalization of insulin probably by modifying the structure of the receptor so that the union with insulin may occur. TSH secreted by the pituitary gland regulates the synthesis and the secretion of $\mathrm{T}_{3}$ and $\mathrm{T}_{4}$. Thyroid hormones are important regulators of energy metabolism and may influence energy processes during physical exercise ${ }^{[41]}$. In this study there was no significant change in the levels of $\mathrm{T}_{3}, \mathrm{~T}_{4}$ or TSH at the third or sixth month compared to values at baseline. Few studies have investigated the effect of yoga exercises on thyroid function ${ }^{[42,43]}$. In a study by Rawal and colleagues who investigated the effect of one month's yoga and physical training (PT) exercise on thyroid function of subjects resident at sea level, a greater increase in thyroidal activity was induced by the conventional PT exercise compared to yoga ${ }^{[42]}$.

\section{CONCLUSION}

In summary, short term lifestyle intervention based on yoga and traditional PT exercise improved glycaemic control due to increased percentage insulin receptor binding. This suggests that yoga and traditional PT exercise interventions produce favourable metabolic effects in individuals with type 2 diabetes mellitus.

\section{REFERENCES}

1. Olefsky, J.M and J.J. Nolan, 1995. Insulin resistance and non-insulin-dependent diabetes mellitus: cellular and molecular mechanisms. Am. J. Clin. Nutr., 61: 1054 -1057.

2. Kahn, C.R., 1996. New concepts in the pathogenesis of diabetes mellitus. Adv. Intern. Med., 41: 285- 321.

3. 3. Zimmet, P.Z., D.J. McCarty and M.P. de Courten, 1997. The global epidemiology of noninsulin- dependent diabtes mellitus and the metabolic syndrome. Journal of Diabetes and its Complications., 11: 60 - 68.

4. Horton, E. S., 1995. NIDDM - the devastating disease. Diabetes Res. Clin. Pract., 28: 3-11.

5. 5. Dela, F., T. Plough, A. Handberg, L. N. Petersen, J. J. Larsen, K. J. Mikines and H. Galla, 1994. Physical training increases muscle GLUT-4 protein and mRNA in patients with NIDDM. Diabetes., 43: $862-865$. 
6. De Feo, P., C. Di Loreto, A. Ranchelli, C. Fatone,. Gambelunghe and P. Lucidi, 2006. Exercise and diabetes. Acta. Biomed., 77 (Suppl 1): $14-17$.

7. Su, C.F., Y.Y. Chang, H.H. Pai, I.M. Liu, C.Y. Lo and J.T. Cheng, 2005. Mediation of betaendorphin in exercise-induced improvement in insulin resistance in obese Zucker rats. Diabetes Metab. Res. Rev., 21: 175 - 182.

8. Benecke, H., H. Topak, H. A. von zur Muhlen and F. Schuppert, 2000. A study on the genetics of obesity of obesity: influence of polymorphisms of the beta-3-adrenergic receptor and insulin receptor substrate 1 in relation to weight loss, waist to hip ratio and frequencies of common cardiovascular risk factors. Exp. Clin. Endocrinol. Diabetes., 2000; 108: 86-92.

9. Maegawa, H., A. Kashiwagi and Shigeta, 1995. Obesity as a risk factor for developing non-insulin dependent diabetes mellitus obesity and insulin resistance. Nippon Naibunpi Gakkai Zasshi., 71: 97 $-104$.

10. Trischitta, V., 1989. Defects in insulin-receptor internalization and processing in monocytes of obese subjects and obese NIDDM patients. Diabetes., 38: 1579 - 1584.

11. Sesti, G., 1996. Delayed intracellular dissociation of the insulin-receptor complex impairs receptor recycling and insulin processing in cultured Epstein-Barr virus-transformed lymphocytes from insulin-resistant subjects. Diabetologia., 39: 289- 295

12. Brillon, D.J., G.R. Freidenberg, R.R. Henry and J.M. Olefsky, 1989. Mechanism of defective insulin-receptor kinase activity in NIDDM. Evidence for two receptor populations. Diabetes., 38:397- 403.

13. Rosmond, R. and P. Bjorntorp, 2000. The hypothalamic-pituitary-adrenal axis activity as a predictor of cardiovascular disease, type 2 diabetes and stroke. J. Intern. Med., 247: 188- 197.

14. Tsai, S.T., C.L. Li, C.H. Chen and P. Chou, 2000. Community-based epidemiological study of glucose tolerance in Kin-Chen, Kinmen: support for a new intermediate classification. J. Clin. Epidemiol., 53: 505 - 510

15. Damodaran, A., A. Malathi, N. Patil, N. Shah, N, Suryavansihi and S. Marathe, 2002. Therapeutic potential of yoga practices in modifying cardiovascular risk profile in middle aged men and women. J. Assoc. Physicians India., 50: 633 - 640
16. Jatuporn, S., S. Sangwatanaroj, A.O. Saengsiri, S. Rattanapruks, S. Srimahachota, W. Uthayachalerm, W. Kuanoon, O. Panpakdee, P. Tangkijvanich and P. Tosukhowong, 2003. Shortterm effects of intensive lifestyle modification program on lipid peroxidation and antioxidant systems in patients with coronary artery disease. Clin. Haemorheol. Microcirc., 29: 429 - 436.

17. Malhotra, V., S. Singh, K.P. Singh, P. Gupta, S.B. Sharma, S.V. Madhu and O.P. Tandon, 2002. Study of yoga asanas in assessment of pulmonary function in NIDDM patients. Indian J. Physiol. Pharmacol., 46: 313 - 320

18. Agrawal, R.P., R. Aradhana, S. Hussain, R. Beniwal, M. Sabir, D.K. Kochar and R.P. Kothari, 2003. Influence of yogic treatment on quality of life outcomes, glycaemic control and risk factors in diabetes mellitus. International Journal of Diabetes in Developing Countries., 23: $130-134$

19. Begg, C., M. Cho, S. Eastwood, R. Horton, D. Mother, I. Olkin, R. Pitkin, D. Rennie, K.F. Schulz, D. Simel and D.F. Stroup, 1996. Improving the quality of reporting of randomized controlled trials: the CONSORT statement. J.A.M.A., 276: 637- 639

20. Evered, D.C., 1974. Meatabolic and Endocrinologic complications in BetaThalassemia. Clinics in Endocr. and Metab., 3: 425 -450 .

21. Olefsky, J.M and G.M. Reaven, 1974. The human lymphocyte: a model for the study of insulinreceptor interaction. J. Clin. Endocrinol. Metab., 38:554-560

22. Brock, P., 1978. Clinical anaysis of toxoxifen, an anti-neoplastic agent in plasma. Clinical Chemistry., 24: 1595-1598.

23. Gambir, K.K., J. A. Archer, and L. Carter, 1977. Insulin receptor assay for human erytrocytes. Clin. Chem., 23:1590 -1595.

24. Larsen, J.J., F. Dela, M. Kjaer and H. Galbo, 1997. The effect of moderate exercise on postprandial glucose homeostasis in NIDDM patients. Diabetologia., 40:447- 453.

25. Sahay, B.K., 1994. Yoga and diabetes. Novo Nordisk Diabetes Update 94 Proceedings. Ed. Anil Kapur, Publ. Health Centre Care Communications, Bombay., 159 - 167.

26. Sahay, B.K., B. Sadasivodo, R. Yogi and P.S. Raju, 1982. Biochemical parameters in normal volunteers before and after yogic practices. Ind. J. Med. Res., 76: 144 - 148 
27. Kamei, T., Y. Toriumi, H. Kimura, S. Ohno, H. Kumano and K. Kimura, 2000. Decrease in serum cortisol during yoga exercise is correlated with alpha wave activation. Percept. Mot. Skills., 90:1027 - 1032 .

28. Trischitta, V., F. Giorgino, L. Frittitta, R. Scalisi and R. Vigneri, 1993. Relationship between insulin receptor tyrosin kinase activity and internalization in monocytes of non- insulin dependent diabetes mellitus patients. Metabolism., 42: 882 - 887 .

29. Sahay, B.K., 2007. Role of yoga in diabetes. J.A.P.I., 55: 121 - 126. 30. Porte, D. Jr. and S.E. Kahn, 1995. The key role of islet dysfunction in type II diabetes mellitus. Clin. Invest. Med., 18: 247- 254.

30. Farese, R.V., 2002. Function and dysfunction of aPKC isoforms for glucose transport in insulinsensitive and insulin-resistant states. Am. J. Physiol. Endocrinol. Metab., 283: E1 - E11

31. Haffner, S.M., 2000. Obesity and the metabolic syndrome: the San Antonio Heart Study. Br. J. Nutr., 83: S67- S70.

32. Wannamethee, S.G., A.G. Shaper, and K.G. Alberti, 2000. Physical activity, metabolic factors, and the incidence of coronary heart disease and type 2 diabetes. Arch. Intern. Med., 160: 2108 $-2116$

33. Lee, Z.S., J.A. Critchley, J.C. Chan, P.J. Anderson, G.N. Thomas, R. P. Young, T.Y. Chan and B. Tomlinson, 2000. Obesity is the key determinant of cardiovascular risk factors in the Hong Kong Chinese population: cross-sectional clinic-based study. Hong Kong Med. J., 6: 13- 23

34. Simonen, P., H. Gylling, A.N. Howard and T.A. Miettinen, 2000. Introducing a new component of the metabolic syndrome: low cholesterol absorption. Am. J. Clin. Nutr., 72: 82- 88
35. Durrington, P.N., 1999. Diabetic dyslipidaemia. Baillieres Best. Pract. Res. Clin. Endocrinol. Metab., 13: 265 - 278.

36. Sahay, B.K., 1994. Role of yogic principles in the prevention of NIDDM in Abstracts of the $15^{\text {th }}$ International Diabetes Federation Congress at Kobe, 95.

37. Manjunatha, S., R.P. Vempati, D. Ghosh and R.L. Bijlani, 2005. An investigation into the acute and long-term effects of selected yogic postures on fasting and postprandial glycaemia and insulinemia in healthy young subjects. Indian $\mathrm{J}$. Physiol. Pharmacol., 49: 319 - 324.

38. Moller, D.E., and J.S. Flier, 1991. Insulin resistance - Mechanisms, syndromes and implications. N. Engl. J. Med., 325: 938-948

39. Lu, G., 1993. Changes in circulating lymphocyte triiodothyronine receptors in diabetes mellitus. Zhonghua Yi Xue Za Zhi., 73:517- 519

40. Kanaka - Gantenbein, C., 2005. The impact of exercise on thyroid hormone metabolism in children and adolescent. Horm. Metab. Res., 37: $563-565$.

41. Gupta, N., S. Khera, R.P. Vempati, R. Sharma and R.L. Bijlani, 2006. Effect of yoga based on lifestyle intervention on state and trait anxiety. Indian J. Physiol. Pharmacol., 50: 41 - 47.

42. Rawal, S.B., M.V. Singh, A.K. Tyagi, W. Selvamurthy and B.N. Chaudhuri, 1994. Effect of yogic exercises on thyroid function in subjects resident at sea level upon exposure to high altitude. In. J. Biometeorol, 38: 44 - 47. 